\title{
Avaliação da aprendizagem em contextos híbridos educacionais: compartilhando experiências sobre a utilização do mapa conceitual como recurso avaliativo no ensino superior
}

\author{
Evaluation of learning in educational hybrid contexts: sharing experiences about using \\ conceptual map as an evaluation resource in higher education
}

\section{RESUMO}

Lílian Roberta Salustiano França ${ }^{1}$

Cleide Jane de Sá Araújo Costa ${ }^{2}$

Maria Auxiliadora Silva Freitas ${ }^{3}$

No contexto da educação híbrida, o presente artigo tem o objetivo de apresentar um relato de experiência sobre a utilização do mapa conceitual como recurso avaliativo no nível superior de ensino, fornecendo uma visão geral sobre as potencialidades deste instrumento de avaliação. A investigação com base teórico-metodológica foi desenvolvida no âmbito de uma disciplina do curso de Pós-Graduação em Educação de uma universidade pública brasileira, cuja proposta pedagógica estava pautada na perspectiva da avaliação da aprendizagem em espaços híbridos de educação. Foi no desenvolvimento das atividades didáticas desta disciplina e na realização dos seminários temáticos sobre a avaliação da aprendizagem que surgiu o seguinte questionamento norteador deste estudo: que possibilidades avaliativas o mapa conceitual proporciona ao contexto de ensino e aprendizagem, numa perspectiva híbrida? A metodologia envolveu estudos em aportes teóricos, apresentação do seminário, elaboração de mapas conceituais pelos discentes no CmapTools, publicação das atividades no ambiente virtual de aprendizagem (AVA) da disciplina e análise dos dados. As categorias de análise consideradas foram às produções dos mapas conceituais e as interações no AVA, observando nos mapas a sua estrutura, os conceitos principais e secundários, a coerência nas hierarquias e as evidências de uma aprendizagem significativa. Os resultados apontam que no contexto do hibridismo em educação os mapas conceituais são procedimentos avaliativos propícios para desenvolver práticas de ensinar e aprender significativas, além disso, no processo de avaliação, esses recursos oferecem possibilidades para a aprendizagem dos discentes, condicionam a momentos de reflexão contínua e permitem o desenvolvimento de uma avaliação formativo-processual.

\footnotetext{
${ }^{1}$ Mestranda do Programa de Pós-Graduação em Educação da Universidade Federal de Alagoas, Campus A. C. Simões - Maceió / Alagoas, Brasil - lilian_salustiano@ hotmail.com

${ }^{2}$ Professora Associada I da Universidade Federal de Alagoas (UFAL), do Centro de Educação, com atuação no Programa de Pós-Graduação em Educação Brasileira, na linha de pesquisa Tecnologias da Informação e Comunicação na Educação (PPGE). Doutora em Educação pela Université de Provence Aix-Marseille I, e em Linguística (UFAL), mestre em psicologia pela Université de Provence Aix-Marseille I, Bacharel em Administração (UFPB), licenciada em Psicologia (UEPB) - Maceió / Alagoas, Brasil - cleidejanesa@ gmail.com ${ }^{3}$ Professora Associada I da Universidade Federal de Alagoas, do Centro de Educação, com atuação no Programa de Pós-Graduação em Educação Brasileira, na linha de pesquisa Tecnologias da Informação e Comunicação na Educação (PPGE). Doutora em Educação pela Universidade Federal da Bahia (FACED/UFBA), Mestre em Educação pela Universidade Federal da Paraíba (UFPB), Especialista em Metodologia do Ensino Superior e Metodologia Científica (PUC/MG), Licenciada em Pedagogia (UFAL) - Maceió / Alagoas, Brasil afreitasmcz@gmail.com
} 


\title{
QO DEVIR EDUCAÇÃO
}

ISSN: 2526-849X

Palavras-chave: Avaliação da aprendizagem; Educação híbrida; Mapa conceitual.

\begin{abstract}
In the context of hybrid education, this research aims to present an experience report on the use of the concept map as an evaluative resource at the higher education level, providing an overview of the potentialities of this assessment instrument. The research with theoretical and methodological basis was developed within the scope of a Postgraduate Course in Education of a Brazilian public university, whose pedagogical proposal was based on the perspective of learning evaluation in hybrid spaces of education. It was in the development of the didactic activities of this discipline and in the conduction of thematic seminars on the assessment of learning that the following guiding question of this study arose: what evaluative possibilities does the concept map provide to the teaching and learning context, in a hybrid perspective? The methodology involved studies in theoretical contributions, presentation of the seminar, preparation of conceptual maps by students in CmapTools, publication of activities in the virtual learning environment (VLE) of the discipline and data analysis. The categories of analysis considered were the production of the concept maps and the interactions in the VLE, observing in the maps its structure, the main and secondary concepts, the coherence in the hierarchies and the evidences of a significant learning. The results point out that in the context of hybridism in education, concept maps are evaluative procedures propitious to developing meaningful teaching and learning practices. Moreover, in the evaluation process, these resources offer possibilities for the learning of students, and conditions for continuous reflection. and allow the development of a formative-procedural assessment.
\end{abstract}

Keywords: Learning assessment; Hybrid education; Conceitual map.

\section{Introdução}

A educação híbrida é o resultado de uma abordagem combinada e mista, onde as práticas pedagógicas ocorrem em parte numa sala de aula presencial e em outra parte por meio do ensino on-line (HORN; STAKER, 2015). Esse processo educativo é complexo e ao mesmo tempo exige do professor habilidades e competências para trabalhar mesclando o ensino presencial e a distância.

Esse contexto educativo permite a introdução das Tecnologias Digitais da Informação e Comunicação (TDIC) e suas contribuições nos processos escolares, viabilizando novos e diferentes métodos de avaliação da aprendizagem (RODRIGUES, 2015). Neste sentido, os inúmeros recursos tecnológicos trabalhados na educação híbrida, podem ser utilizados como estratégias didáticas, meios de aprendizagem e procedimentos de avaliação.

O presente artigo trata de um relato de experiência, cujo objetivo é apresentar a utilização dos mapas conceituais como procedimentos avaliativos, além de mostrar as 


\section{QO DEVIR EDUCAÇÃO}

ISSN: 2526-849X

potencialidades do trabalho com esse recurso tecnológico-pedagógico num contexto híbrido do Ensino Superior. A obtenção dos dados da pesquisa se deu no âmbito da disciplina de "Avaliação da aprendizagem no contexto da educação presencial e a distância fundamentada no uso das TIC", do Programa de Pós-Graduação em Educação, a qual era composta por duas docentes doutoras em Educação e quatorze discentes de Mestrado e Doutorado matriculados na disciplina.

O caminho metodológico envolveu as etapas de estudos teórico-metodológicos, apresentação do seminário, elaboração de mapas conceituais pelos discentes no programa CmapTools, publicação dos mapas de conceitos no Guinteract, ambiente virtual de aprendizagem (AVA) da disciplina, e análise dos dados. As categorias de análise consideradas foram às produções dos mapas conceituais e as interações no AVA, observando nas representações conceituais a sua estrutura, os conceitos principais e secundários, a coerência entre as hierarquias e as evidências de aprendizagem significativa ${ }^{4}$.

Um dos principais conceitos desenvolvidos neste estudo é sobre a avaliação da aprendizagem em contextos de educação híbrida. Nesse sentido, o trabalho prioriza a abordagem da avaliação formativo-processual com base nos autores Freitas (2009); Hadji (2001); Hoffmann (1991), (1993), (1998) e (2001); Luckesi (1997), (2000) e (2011); Silva (2006). Na proposta de educação híbrida o estudo apresenta os modelos dessa abordagem educativa, as suas características peculiares e as formas de avaliação da aprendizagem que fundamenta esta tendência de educação. Nessa perspectiva, para embasar esta seção foram utilizados como aportes teóricos: Christensen et al (2013); Bacich et al (2015); Hoffmann (2001); Gomes (2014); Horn e Staker (2015); Moran (2015); Rodrigues (2015); Spinardi e Both (2018); e Valente (2018).

Nesse contexto de discussão, os mapas conceituais ganham revância como recursos avaliativos, fundamentados nos pressupostos de Freitas (2009); Moreira e Masini (2011) e Moreira (2012), os quais argumentam sobre os mapas conceituais e suas especificidades, também explicam os tipos de avaliação da aprendizagem que podem fazer parte do ato pedagógico mediante o uso deste recurso.

O artigo também está sistematizado com reflexões acerca do que é a educação híbrida e sua proposta de avaliação; traz concepções referente à utilização dos mapas conceituais e

\footnotetext{
${ }^{4}$ Conforme explica Moreira e Masini (2001), o conceito mais importante da teoria ausubeliana é a aprendizagem significativa, pois ela é um processo em que a nova informação se relaciona com os conhecimentos preexistentes na estrutura cognitiva do indivíduo, os quais Ausubel os definem como subsunçores. É nessa combinação que ocorre a aprendizagem significativa.
} 


\section{OO DEVIR EDUCAÇÃO}

ISSN: 2526-849X

suas possibilidades avaliativas; apresenta o caminho metodológico para obter os dados da pesquisa e a análise dos mapas conceituais produzidos pelos discentes na ação pedagógica; finaliza com ponderações sobre as contribuições de trabalhar com os mapas conceituais em contextos híbridos de educação.

\section{Avaliação da aprendizagem no processo híbrido de educação}

A avaliação da aprendizagem é uma ação complexa que está presente em qualquer contexto educacional, seja ele presencial, on-line ou híbrido. Ela não se efetiva no simples julgamento de valor, determinando se os alunos são capazes ou não de prosseguir nos seus estudos futuros, pelo contrário, a avaliação é parte integrante do processo de ensino aprendizagem e está comprometida com a busca de melhores resultados para as práticas escolares.

Para Luckesi (2011) a avaliação da aprendizagem é um componente do ato pedagógico, pois está integrada aos elementos essenciais que fazem parte da ação educativa na escola: o planejamento das ações, a execução do que foi planejado e a avaliação dos resultados. Na perspectiva do autor, a avaliação não é uma ação espontânea que ocorre sem determinações de metas, ela é uma prática intencionalmente planificada que contém objetivos claros a propósito do que se pretende alcançar, e orientações que norteiem a consecução do trabalho pedagógico.

Nessa conjuntura, o conceito de avaliação da aprendizagem é amplo, pois também está associado a um ato político que se faz com intencionalidade pedagógica; é uma ação de escolhas conscientes, cuja finalidade é o compromisso com a aprendizagem e formação do cidadão.

De acordo com Hoffmann (2001, p.10) “Avaliação é substancialmente reflexão, capacidade única e exclusiva do ser humano, de pensar sobre seus seres, influindo e sofrendo influências pelo seu pensar e agir." Nessa concepção, o ponto chave da avaliação é a ação reflexiva do professor, que num contexto escolar faz observações constantes do processo didático-pedagógico, reflete sobre as práticas de ensinar e aprender investigadas e promove 


\section{OO DEVIR EDUCAÇÃO}

ISSN: 2526-849X

atuações que estejam a serviço da melhoria da ação pedagógica e, consequentemente, da aprendizagem dos alunos.

Sob essa perspectiva, Hoffmann (2011) acredita que acredita que a avaliação da aprendizagem é como uma seta que conduz o educador e o educando para o melhor caminho a ser percorrido. Sendo assim, a ação avaliativa que direciona para o futuro se realiza num ambiente coletivo mediante o acompanhamento contínuo dos percursos individuais dos alunos. Esta visão do modo singular de aprendizagem dos estudantes direcionará o professor a escolher metodologias, estratégias e instrumentos que favoreçam a evolução de cada sujeito envolvido nas etapas educativas.

Na mesma consonância desses pressupostos, Silva (2006, p.28) defende que na educação on-line "a avaliação [...] é a reflexão transformada em ação. Ação que nos impulsiona a novas reflexões." De acordo com o autor, o contexto online merece práticas avaliativas dinâmicas, que valorizam a autonomia, a ação dialógica, a participação, a colaboração e a reflexão constante, isso requer a ressignificação da avaliação da aprendizagem centrada em exames pontuais e em mecanismos de classificação dos estudantes.

Nesse sentido, Silva (2006) fundamenta-se na abordagem de avaliação mediadora defendida por Hoffmann (2004), a qual está associada ao modelo de avaliação libertadora cuja função insere-se na prática dialógica, interativa e colaborativa entre os sujeitos do processo de ensino aprendizagem. Nessa linha de pensamento, a avaliação é desenvolvida na coletividade da sala de aula, mediante reflexões conscientes entre professores e alunos sobre a trajetória da construção do conhecimento, e a respeito dos melhores caminhos que a prática educativa necessita tomar para promover a aprendizagem de todos.

Todos esses pressupostos de avaliação da aprendizagem destacados anteriormente, entram em sintonia com as potencialidades da educação híbrida, uma vez que, este modelo não se limita a realização de práticas classificatórias, de verificar a aprendizagem dos alunos com o propósito na aprovação/reprovação, pelo contrário, no contexto híbrido a prática de avaliação se faz por meio da reflexão permanente que serve para reconfigurar o ato pedagógico.

Segundo Rodrigues (2015, p.124) "no modelo de ensino híbrido, a tecnologia viabiliza novos e distintos métodos de avaliação, como recursos diversos, sistemas de cooperação ou de registro individual de resultados, formas variadas de entrega e apresentação.” Isso significa 


\section{QO DEVIR EDUCAÇÃO}

ISSN: 2526-849X

que, na abordagem híbrida, os variados recursos convencionais e digitais de ensino aprendizagem também se convertem em instrumentos e procedimentos avaliativos, ou seja, tanto um seminário quanto uma atividade de elaboração de um mapa conceitual num programa de computador podem oferecer ao professor evidências de que o aluno aprendeu ou não um conteúdo escolar.

Outra questão apontada por Rodrigues (2015) sobre a avaliação da aprendizagem na educação híbrida, é a mudança de foco no processo de avaliação, que conforme as características deste modelo, recai principalmente sobre o aluno. Para o autor, manter o foco do processo de ensino aprendizagem no aluno é o mesmo que promover a personalização da aprendizagem mediante a ação avaliativa, isto é, trabalhar com cada estudante respeitando o seu ritmo individual, promover processos de feedback para deixá-los conscientes de seus erros e acertos e, por fim, buscar outras alternativas que superem as dificuldades de aprendizagem.

\subsection{Educação híbrida e suas perspectivas de avaliação da aprendizagem}

O surgimento da educação híbrida está fortemente atrelado ao e-leaning e a sua união aos processos de ensino aprendizagem convencionais. Segundo os estudos de Horn e Staker (2015), a ascensão do ensino on-line teve início com programas educacionais ofertados a um número reduzido de estudantes, nesse sentido, foi considerando as pesquisas que analisavam que mais de $90 \%$ dos estudantes dependeriam de supervisão adulta no âmbito escolar, que diretores e professores de escolas inovadoras buscaram articular o ensino on-line com a experiência do espaço físico tradicional para oferecer a estes $90 \%$ de estudantes às potencialidades do ensino on-line. Esta integração entre as duas modalidades de educação gerou o termo que conhecemos hoje como blended learning ou ensino híbrido (HORN; STAKER, 2015).

O ensino híbrido adentrou no vocabulário das escolas norte-americanas aproximadamente no início do século XXI, e vem se consolidando como uma das tendências mais importantes para a educação deste século (GOMES, 2014). Sua implantação nos processos educativos não é temporária, pois não se trata de um modismo, pelo contrário, é 


\section{QO DEVIR EDUCAÇÃO}

ISSN: 2526-849X

uma proposta de educação que está crescendo exponencialmente e veio para ficar (VALENTE, 2015).

Diversas acepções acerca da educação híbrida são encontradas na literatura científica, mas de acordo com Bacich et al $(2015$, p.52) todas elas apresentam num sentido amplo "[...] a convergência de dois modelos de aprendizagem: o modelo presencial, em que o processo ocorre em sala de aula, [...] e o modelo on-line que utiliza as tecnologias digitais para promover o ensino." Nesta conjuntura, a educação híbrida nasce da combinação complexa e intencional entre processos formativos presenciais e virtuais, que se complementam e proporcionam diferentes experiências de ensino e aprendizagem.

Moran (2015) apresenta a educação híbrida como a junção de vários tipos de misturas e mesclas que favorecem inúmeras oportunidades para as práticas de ensinar e aprender. Para o autor, a mistura que ocorre no ensino híbrido vai além da integração entre o presencial e o on-line, entre as metodologias ativas e entre vários espaços educacionais, a este respeito, sua concepção teórica se assemelha a definição destacada por Bacich et al (2015), quando apresenta a educação híbrida como um processo contínuo de aprendizagem, que ocorre de diferentes formas, em diferentes tempos e espaços, mediante a participação de diversos públicos e na combinação de uma variedade de atividades e metodologias.

Conforme Christensen et al (2013) a educação híbrida está categorizada em quatro modelos distintos como podemos compreender no (quadro 1).

\section{Quadro 1: Modelos e definição da educação híbrida}

\begin{tabular}{|l|l|}
\hline EDUCAÇÃO HÍBRIDA & DEFINIÇÃO \\
\hline MODELOS & $\begin{array}{l}\text { É aquele em que durante um curso ou disciplina os alunos } \\
\text { revezam entre as modalidades presencial e on-line, } \\
\text { atendendo a um critério fixo ou de acordo com as } \\
\text { orientaçães do professor. O modelo de rotação está } \\
\end{array}$ \\
& $\begin{array}{l}\text { subdividido em quatro propostas educativas: Rotação por } \\
\text { Estações; Laboratório Rotacional; Sala de Aula Invertida } \\
\end{array}$ \\
& e Rotação Individual. \\
\hline Flex & É aquele em que a maior parte do processo educativo \\
\hline
\end{tabular}




\begin{tabular}{|l|l|}
\hline & $\begin{array}{l}\text { ocorre de forma on-line, podendo ser desenvolvido em } \\
\text { ambientes presenciais por alguns momentos, conforme a } \\
\text { necessidade dos alunos e sob constante orientação do } \\
\text { professor. }\end{array}$ \\
\hline À la Carte & $\begin{array}{l}\text { É aquele no qual os alunos participam de cursos } \\
\text { inteiramente on-line nas unidades físicas de ensino ou em } \\
\text { outros locais. Neste caso, os cursos on-line não servem } \\
\text { para substituir a sala de aula convencional. }\end{array}$ \\
\hline Virtual Enriquecido & $\begin{array}{l}\text { É aquele em que ocorre no âmbito do sistema de ensino } \\
\text { integral, e busca complementar o aprendizado dos alunos } \\
\text { sobre os conteúdos das disciplinas. Este contexto promove } \\
\text { o melhoramento do aprendizado do aluno por meio do } \\
\text { acesso a conteúdos e atividades on-line. }\end{array}$ \\
\hline
\end{tabular}

Fonte: adaptado de Christensen et al (2013).

Conforme o quadro acima, a educação híbrida fundamenta-se na realização de quaisquer modelos exemplificados no (quadro 1). Ela pode ser implementada considerando as contribuições de apenas uma destas categorias ou pode ser trabalhada com a mistura entre modelos, nesse sentido, se num contexto híbrido de educação não é possível enquadrar a proposta educativa em um dos modelos citados por Christensen et al (2013), significa dizer que, o docente optou por realizar uma mescla de modelos em seu ato pedagógico.

Ainda nesse contexto, Horn e Staker (2015) destacam que eles podem possuir potenciais sustentáveis, preservando as contribuições da sala de aula convencional e acrescentando as potencialidades do ensino on-line; ou podem se encaixar nas inovações disruptivas que visam romper aos poucos com as práticas convencionais de ensino aprendizagem, buscando substituir por completo os sistemas estabelecidos. Sendo assim, os modelos de Rotação por Estações, Laboratório Rotacional e Sala de Aula Invertida são mais sustentáveis, enquanto os modelos de Rotação Individual, Flex, À la Carte e Virtual Enriquecido enquadram-se na disrupção ${ }^{5}$.

\footnotetext{
5 Para Horn e Staker (2015), as inovações disruptivas no âmbito educacional surgem para atender as necessidades do processo pedagógico e posteriormente, substituir por completo a abordagem de ensino convencional.
}

Revista Devir Educação, Lavras, vol.3, n.2, p.136-155 jul./dez., 2019. 


\section{OO DEVIR EDUCAÇÃO}

ISSN: 2526-849X

O trabalho com a educação híbrida pressupõe a prática da personalização da aprendizagem, uma característica peculiar deste contexto educacional. Para Valente (2018, p.33) “[...] na aprendizagem personalizada, o aluno está envolvido na criação de atividades de aprendizagem que estão adaptadas as suas preferências, aos interesses pessoais e à curiosidade inata." Em outras palavras, personalizar um processo de aprendizagem significa promover experiências pedagógicas centradas nos alunos, considerando que cada um deles tem sua maneira própria de aprender.

Complementando os argumentos de Valente (2018), Bacich et al (2015, p.51) demonstra que "aspectos como o ritmo, o tempo, o lugar e o modo como aprendem são relevantes quando se reflete sobre a personalização do ensino." Para os autores, uma educação personalizada é aquela que atende as necessidades de todos os estudantes, permitindo que os sujeitos do processo de ensino aprendizagem tenham voz participativa e escolham juntos as situações educativas que desejam vivenciar.

Nesse sentido, o ato de avaliar também compõe as etapas de personalização do ensino, uma vez que, é uma ação que está comprometida com a aprendizagem dos alunos, por isso evidencia novos rumos para prática didático-pedagógica, que tenham a intencionalidade de promover a melhoria do processo educativo.

\section{Os mapas conceituais como procedimentos avaliativos}

Os mapas conceituais ou mapas de conceitos "podem ser vistos como diagramas hierárquicos que procuram refletir a organização conceitual de uma disciplina ou parte de uma disciplina.” (MOREIRA; MASINI, 2011, p.51). É um recurso que se insere na teoria ausubeliana da aprendizagem significativa, na qual a aprendizagem de um conceito só faz sentido para o estudante quando ele consegue articular a nova informação estudada com os conceitos, ideias e proposições preexistentes em sua estrutura cognitiva. Sendo assim, os "subsunçores" ou conhecimentos prévios dos alunos são uma espécie de âncora que se alia ao novo conhecimento e amplifica a cognição.

A mesma função ocorre na elaboração de um mapa conceitual, pois ele não é um produto pronto e acabado. Assim como a cognição humana vai sendo ampliada com a junção 


\section{QO DEVIR EDUCAÇÃO}

ISSN: 2526-849X

dos subsunçores com a nova informação, da mesma forma os mapas de conceitos vão se reestruturando a cada produção e trazendo evidências que o aluno está aprendendo significativamente o conteúdo (MOREIRA, 2012).

Para Moreira (2012), os mapas conceituais têm suas características próprias e diferem do mapa mental, justamente por causa da interligação hierárquica que os conceitos apresentam. Entretanto, para Ontoria et.al. (2008), os mapas mentais podem ser integrados a uma aprendizagem significativa, no mesmo nível que os mapas conceituais, uma vez que representam um processo de reorganização das estruturas cognitivas existentes.

$\mathrm{Na}$ estruturação do mapa conceitual existem os conceitos contextualmente mais importantes, àqueles que estão localizados no topo das hierarquias e os conceitos secundários que estão postos na parte inferior das representações conceituais (MOREIRA, 2012). Além destas peculiaridades, os mapas de conceitos têm em sua composição as figuras geométricas, as linhas, as setas de ligação, as palavras-chave, os destaques dos conceitos mais inclusivos e a coloração das hierarquias.

No ato pedagógico, os mapas conceituais apresentam várias finalidades educacionais, pois são considerados como instrumentos não convencionais de ensino e avaliação da aprendizagem. Inclusive, no contexto avaliativo o trabalho com este recurso favorece o desenvolvimento de qualquer tipo de avaliação, seja ela diagnóstica para indicar como está o desenvolvimento e aprendizagem dos alunos, formativa para buscar novos caminhos pedagógicos que levem a uma aprendizagem significativa, e somativa para definir conceitos e/ou notas que designem as competências e habilidades adquiridas no processo formativo (FREITAS, 2009).

Para Freitas (2009), um dos procedimentos para expressar uma avaliação qualitativa e formativa da aprendizagem são os mapas conceituais, pois eles proporcionam ao professor informações sobre o conhecimento prévio dos alunos em avaliações diagnósticas; são recursos que podem ser trabalhados ao longo do processo de ensino aprendizagem favorecendo a realização da avaliação contínua; e podem ressaltar os resultados obtidos com o processo educativo mediante uma avaliação somativa.

Nesse construto teórico, podemos dizer que o ato avaliativo com mapas conceituais é realizado na educação híbrida mediante a observação e reflexão das evidências de aprendizagem identificadas na representação conceitual. Tal processo, propicia ao professor verificar os termos conceituais que o aluno conseguiu compreender, e como o aluno "[...] 


\section{QO DEVIR EDUCAÇÃO}

ISSN: 2526-849X

estrutura, hierarquiza, diferencia, relaciona discrimina, integra conceitos de uma unidade de estudo, tópico, disciplina, etc.” (MOREIRA, 2012, p.20). Por outro lado, essa abordagem requer do professor uma atitude questionadora, face a sua prática pedagógica, e aos critérios definidos na ação avaliativa.

\section{Caminho metodológico}

Com vistas a atender a questão que norteou este estudo, ou seja, que possibilidades avaliativas o mapa conceitual proporciona ao contexto de ensino e aprendizagem, numa perspectiva híbrida?, ratificamos o contexto educativo investigado: numa disciplina do Programa de Pós-Graduação em Educação (PPGE), a qual seguia a proposta de educação híbrida combinando processos formativos presenciais e on-line.

A disciplina "Avaliação da aprendizagem no contexto da educação presencial e a distância fundamentada no uso das TIC", permitia o estudo e aprofundamento em temáticas relacionadas à avaliação da aprendizagem realizadas em vários contextos educacionais, como também oportunizava aos discentes de mestrado e doutorado conhecer diversos recursos avaliativos mediante a realização dos seminários temáticos.

A pesquisa insere-se na abordagem qualitativa, permitindo acompanhamento direto do pesquisador no lócus de investigação e considerando a perspectiva dos participantes. (LÜDKE; ANDRÉ, 1986). Nesse sentido, o caminho metodológico para construção deste estudo envolveu as etapas de pesquisa teórico-metodológica apresentação do seminário com o tema dos mapas conceituais como instrumentos avaliativos, elaboração de mapas conceituais pelos discentes no programa CmapTols, publicação das atividades no Guinteract, ambiente virtual de aprendizagem (AVA) da disciplina, e análise dos dados.

Sendo assim, logo após a mediação dos conhecimentos sobre a educação híbrida, a avaliação da aprendizagem e os mapas conceituais por intermédio do seminário, no laboratório de informática, foi realizado o momento prático com a utilização do software CmapTools, um programa que traz praticidade e facilidade na produção do recurso trabalhado. 


\section{QO DEVIR EDUCAÇÃO}

ISSN: 2526-849X

Seguindo a sequência didática, a mediadora do seminário solicitou que os discentes fizessem a leitura do texto "O ensino híbrido e a avaliação da aprendizagem no Ensino Superior" de Spinardi e Both (2018), selecionassem os conceitos principais e secundários do texto e realizassem a produção individual de um mapa conceitual. Depois de produzido, o recurso teria que ser publicado no AVA da disciplina.

A experiência resultou em diversos mapas conceituais que foram analisados com base nas concepções dos autores trabalhados neste artigo. Os critérios avaliativos foram os seguintes: a estrutura e organização das representações conceituais; os conceitos principais e secundários apresentados; a coerência entre as hierarquias; e as evidências de aprendizagem significativa observadas no mapa e nas interações que ocorreram no fórum de discussão do AVA trabalhado.

Os critérios de inclusão para a análise dos mapas atenderam apenas as representações conceituais com letras legíveis que facilitassem a leitura, e foram excluídos da análise os mapas cujas palavras foram escritas numa fonte de tamanho menor impossibilitando a visualização dos conceitos apresentados. Sendo assim, entre os seis mapas publicados, apenas quatro foram selecionados para análise.

\section{Análise dos dados}

A base teórica deste estudo apresentou a educação híbrida como um modelo pedagógico educacional que é composto por vários aspectos que se mesclam e ao mesmo tempo se combinam, entre eles estão a educação formal e informal, as metodologias ativas, os diferentes públicos, a interdisciplinaridade, o currículo flexível, a integração de diversos espaços e tempos e a introdução das tecnologias na educação (MORAN, 2015). Nessa conjuntura, verifica-se que na disciplina de "Avaliação da aprendizagem no contexto da educação presencial e a distância fundamentada no uso das TIC", ocorreu em grande parte esta mescla argumentada pelo autor.

O contexto de educação híbrida pesquisado também possui um potencial mais sustentável, uma vez que, não rompe totalmente com as práticas de ensino aprendizagem 


\section{Q1) DEVIR EDUCAÇÃO \\ ISSN: 2526-849X}

convencionais, pelo contrário, alia de maneira harmoniosa as contribuições da educação presencial com as possibilidades da educação online (HORN E STAKER, 2015).

Nesse sentido, variados recursos considerados tradicionais articulados aos tecnológicos potencializam as práticas de ensinar e aprender da educação híbrida. Entre tantos procedimentos de ensino e aprendizagem trabalhados nesse âmbito escolar, podemos citar o mapa conceitual como um recurso que apresenta várias finalidades, podendo ser utilizado como técnica didática, recurso de aprendizagem e meio de avaliação (MOREIRA, 2012).

Nesta perspectiva, foi reconhecido na experiência didática desta pesquisa que o ato pedagógico também se faz mediante a avaliação da aprendizagem com mapas conceituais, identificando as evidências de aprendizagem significativa, e conforme defende Hoffmann (2001), também serve para levar os sujeitos do processo educativo a momentos de reflexão constante, e auxilia na busca de setas que norteiem o caminho mais apropriado para efetivação da aprendizagem dos alunos.

Desta maneira, os mapas conceituais produzidos pelos alunos de Pós-Graduação em Educação participantes da disciplina em pauta, apresentaram evidências de aprendizagem significativa, como explica Moreira (2012), pois eles apreenderam todas as coordenadas de elaboração do recurso no ato do seminário e conseguiram articular os novos conhecimentos com as informações presentes em sua estrutura cognitiva. Isto é notável na (Figura 1) quando o discente codificado de (E1) traz para as hierarquias do mapa os modelos de educação híbrida, os quais não foram mencionados na apresentação, mas fazia parte do seu conhecimento prévio.

Figura 1: Primeiro mapa conceitual publicado no AVA. (E1). 


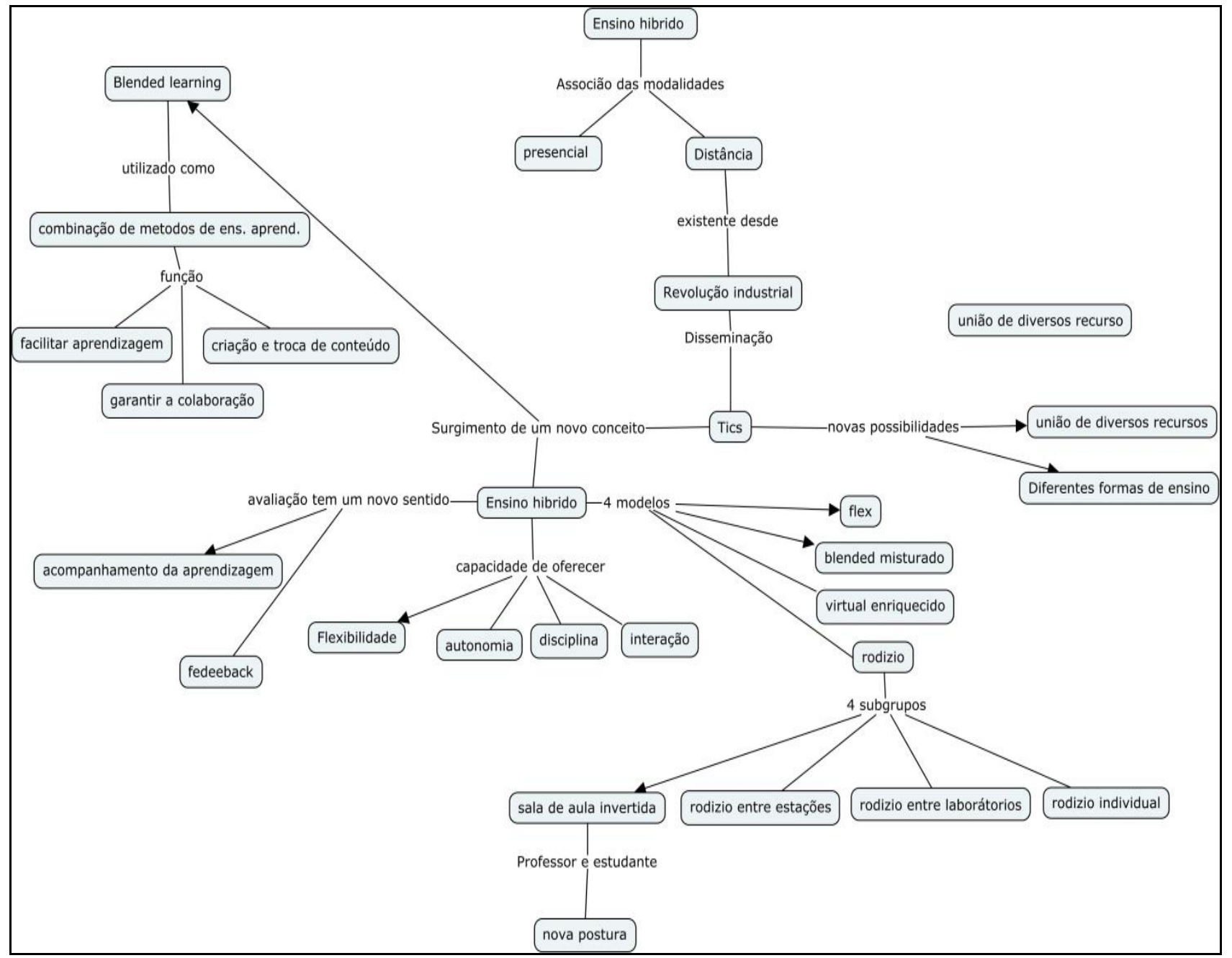

Fonte: Mapa conceitual elaborado por E1.

No que se refere à estrutura do mapa de conceitos de E1, o discente apresentou de forma exitosa os conceitos primários e secundários, hierarquizando conforme o grau de significação, entretanto, poderia destacar as formas geométricas das hierarquias com colorações diferentes para facilitar a visualização e compreensão do leitor.

Já o mapa conceitual exposto por E2 também trouxe conceitos trabalhados no texto de Spinardi e Both (2018), mas o diferencial desta representação conceitual está na intertextualidade, pois o discente conseguiu fazer a articulação entre as informações do texto científico, os conceitos socializados no seminário e os conhecimentos presentes na sua estrutura cognitiva. Neste sentido, podemos dizer que este mapa conceitual nos traz evidências da aprendizagem significativa, quando o discente utiliza as citações de Rodrigues (2010), Valente (2014) e alguns conceitos sobre o ensino híbrido extraídos do texto de Spinardi e Both (2018) para estruturar o seu mapa conceitual e construir o conhecimento. 
Figura 2: Segundo mapa conceitual publicado no AVA. (E2)

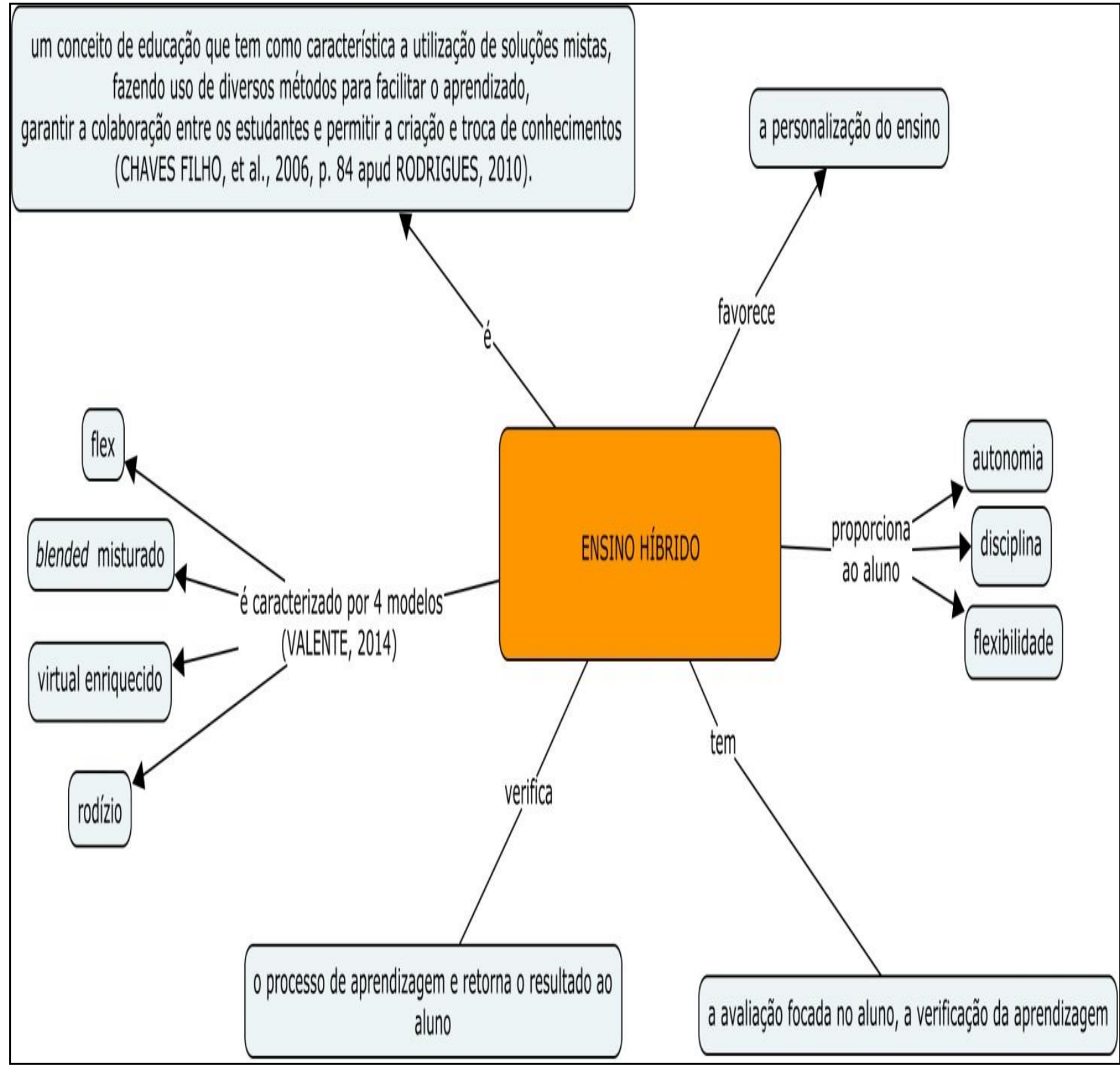

Fonte: Mapa conceitual elaborado por E2.

O mapa conceitual elaborado por E3 traz conceitos como os modelos, as características, as funções, o objetivo e os recursos que podem ser utilizados no Ensino Híbrido, além disso, nota-se no recurso que o discente expõe seus conhecimentos prévios para a elaboração do mapa, principalmente na hierarquia de conceitos que aborda sobre a avaliação. Esta articulação com conhecimentos anteriores está presente na exposição do recurso, pois estas informações foram trabalhadas em outros momentos da disciplina, inclusive durante a leitura de Freitas (2009), quando aborda sobre a avaliação da aprendizagem em ambientes de formação online. 
Figura 3: Terceiro mapa conceitual publicado no AVA. (E3)

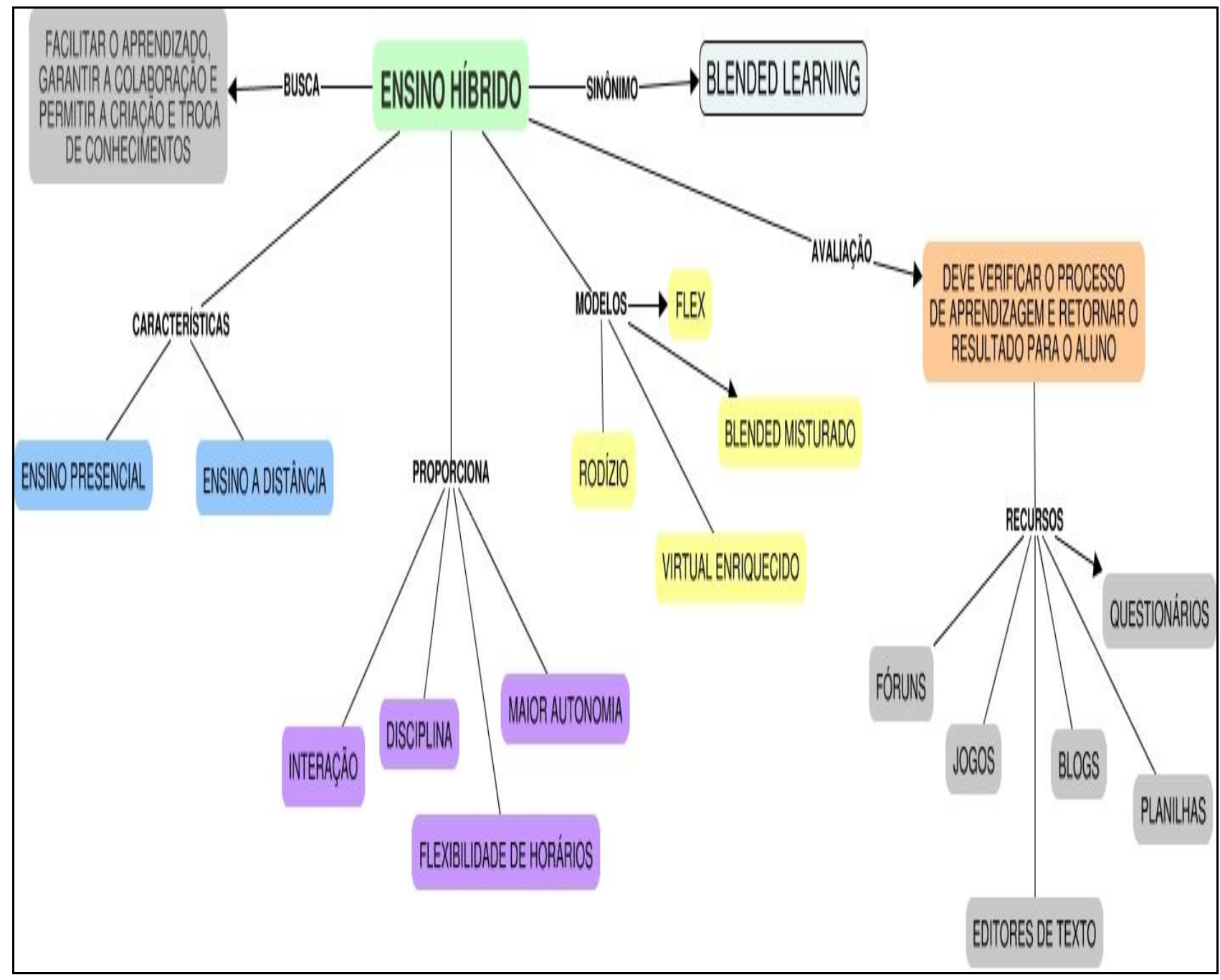

Fonte: Mapa conceitual elaborado por E3.

O discente E4 que elaborou o mapa conceitual contido na (Figura 4), fez alguns argumentos no fórum de discussão antes de publicar o seu mapa de conceitos no AVA, em suas palavras ela relata que utiliza o mapa conceitual na sua prática didático-pedagógica, para promover a aprendizagem e a avaliação. Por este motivo, está explícito na (Figura 4) que ele tem um domínio no processo de elaboração deste recurso.

O mapa conceitual de E4 enquadra-se nos ensinamentos de elaboração de um mapa conceitual apresentados por Moreira (2012), pois está bem organizado, contendo destaque no conceito principal, coloração diferenciada nas hierarquias de conceitos secundários, está composto por setas para facilitar a interpretação do leitor e palavras-chave para articular os 
conceitos. Seu conteúdo também nos oferece evidências de que a discente fez a leitura do texto solicitado, visto que, traz conceitos bem interligados.

Figura 4: Quarto mapa conceitual publicado no AVA. (E4)

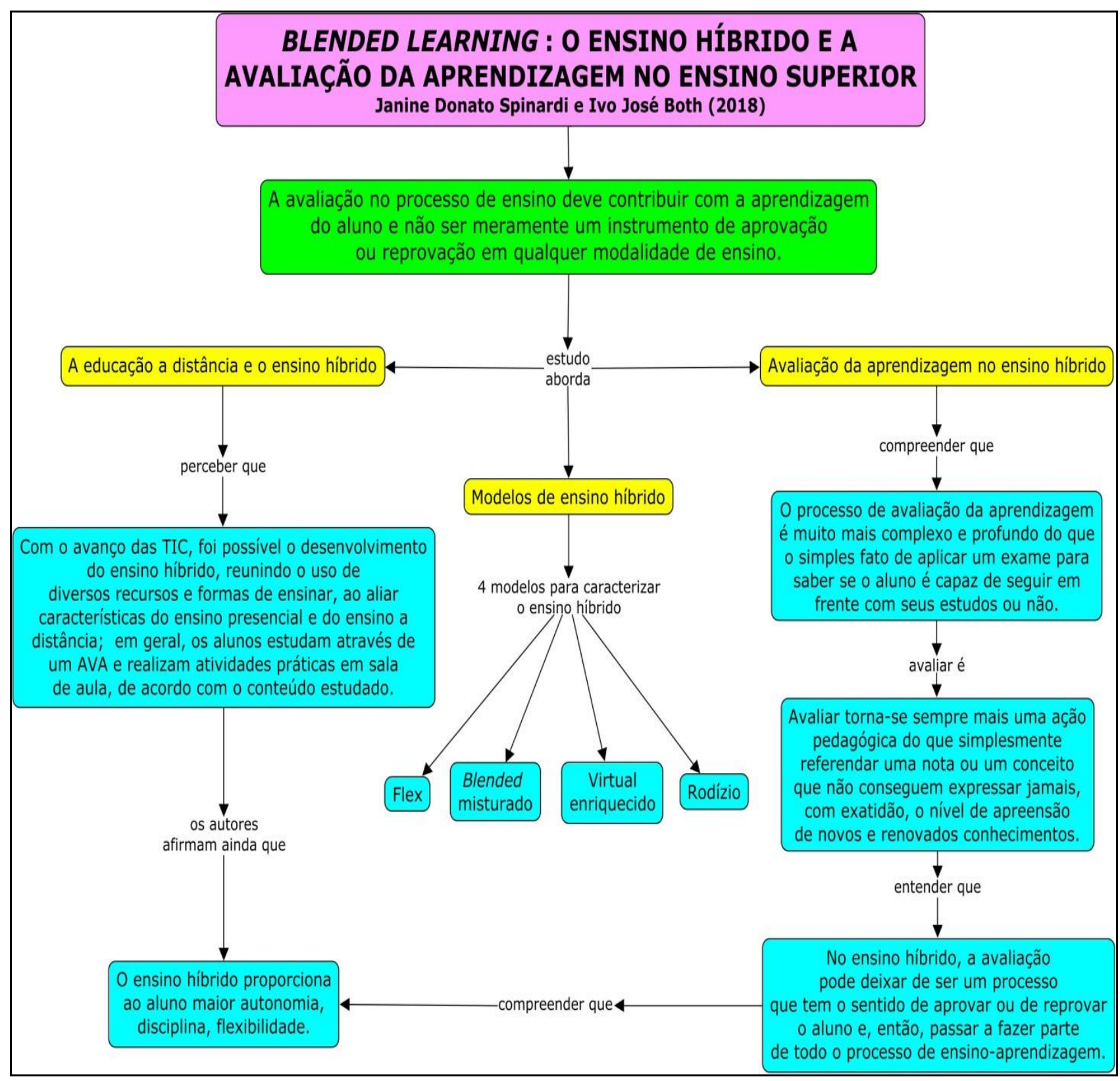

Fonte: Mapa conceitual elaborado por E4.

Contudo, verifica-se nesta experiência didática que o mapa conceitual é mais um procedimento de ensino aprendizagem que direciona a educação híbrida para o trabalho com uma avaliação formativa, aquela defendida por Freitas (2009) como uma avaliação que intervém pedagogicamente na construção de aprendizagens significativas, isto é, um processo 


\section{OO DEVIR EDUCAÇÃO}

ISSN: 2526-849X

avaliativo contínuo que favorece a reflexão e a busca de instrumentos, estratégias e metodologias que colocam o foco educativo no aluno (RODRIGUES, 2015).

\section{Considerações finais}

A educação híbrida é uma tendência pedagógica que teve suas primeiras iniciativas na virada do século XXI, e está se tornando o foco de muitas discussões no campo educacional. As práticas de ensinar e aprender trabalhadas nesse modelo de educação evidenciam também uma abordagem diferente nos processos avaliativos, justamente porque nessa mistura de presencial com virtual, outros recursos pedagógicos estão sendo utilizados no processo de ensino e de aprendizagem.

Em meio a uma infinidade de recursos convencionais da sala de aula presencial e recursos tecnológicos da sala de aula on-line, o mapa conceitual aparece nesse contexto como um procedimento pedagógico que favorece ações didáticas de ensino e aprendizagem, nesse sentido, o professor tanto media conhecimentos na exposição de um mapa conceitual, como solicita aos discentes que realizem atividades de elaboração destes recursos.

Entretanto, os mapas conceituais não possuem apenas as funções de estratégia didática ou recurso de aprendizagem, ele também é um procedimento avaliativo. A respeito das possibilidades avaliativas proporcionadas pela utilização do mapa conceitual, podemos dizer que eles são recursos avaliativos que podem potencializar a educação híbrida, uma vez que, permite uma avaliação qualitativa do conhecimento do aluno, oferece evidências se os estudantes realmente aprenderam ou não os conteúdos conceituais de uma disciplina, possibilita momentos de reflexão da ação, além de favorecer a aprendizagem a significativa.

Portanto, a experiência pedagógica compartilhada neste estudo permitiu identificar que a avaliação no âmbito da educação híbrida tem o compromisso com a aprendizagem dos alunos, acolhendo o "erro" como uma etapa de construção do conhecimento, oferecendo retroalimentações para as atividades realizadas e auxiliando os alunos na construção do conhecimento. Essa é a finalidade do uso do mapa conceitual como recurso avaliativo: abrir outras alternativas que incluam as características da avaliação formativa, contribuindo com a reflexão permanente dos processos que conduzem os alunos para uma melhor aprendizagem. 


\section{Referências}

BACICH, Lilian.; TANZI NETO, Adolfo; TREVISANI, Fernando de Mello. Ensino Híbrido: personalização e tecnologia na educação. Porto Alegre: Penso, 2015.

CHRISTENSEN, Clayton M..; HORN, Michael B.; STAKER, Heather. Ensino Híbrido, uma inovação disruptiva? Uma introdução à teoria dos híbridos. [S.I: s. n.], 2013. Disponível em:http://provir.org/wp-content/uploads/2014/08/PT_Is-K-12-blended-learning--disruptiveFinal.pdf>. Acesso em: 25 abr. 2019.

FREITAS, Maria Auxiliadora Silva. Os estudos hermenêuticos e a sua contribuição na avaliação da aprendizagem que ocorre em ambientes de formação online. In. MERCADO, L. P. L. (Org.). Fundamentos e práticas na educação a distância. Maceió: EDUFAL, 2009, p.79-92.

GOMES, Patrícia. Ensino híbrido é o único jeito de transformar a educação. 2014. Disponível em: <http://porvir.org/ensino-hibrido-e-unico-jeito-de-transformar-educacao/>. Acesso em: 24 abr. 2019.

HOFFMANN, Jussara. Avaliar para promover: as setas do caminho. 9. ed. Porto Alegre: Mediação, 2001.

Avaliação Mediadora: uma prática em construção da pré-escola à universidade. Porto alegre: Mediação, 2004.

HORN, Michael B.; STAKER, Heather. Blended: usando a inovação disruptiva para aprimorar a educação. Porto Alegre: Penso, 2015.

LUCKESI, Cipriano Carlos. Avaliação da aprendizagem: componente do ato pedagógico. São Paulo: Cortez, 2011.

LÜDKE, Menga.; ANDRÉ, Marli. Pesquisa em educação: abordagens qualitativas. São Paulo: Editora EPU, 1986.

MORAN, José. Educação Híbrida: Um conceito-chave para a educação, hoje. In. BACICH, Lilian; TANZI NETO, Alfredo; TREVISANI, Fernando de Mello. Ensino Híbrido: personalização e tecnologia na educação. Porto Alegre: Penso, 2015, p. 27-45.

MOREIRA, Marco Antônio; MASINI, Elcie Fortes Salzano. Aprendizagem significativa: a teoria de David Ausubel. São Paulo: Centauro, 2001.

MOREIRA, Marco Antônio. Mapas conceituais e a aprendizagem significativa. Porto Alegre: RS, 2012. Disponível em: < https://www.if.ufrgs.br/ moreira/mapasport.pdf>. Acesso em: 01 maio 2019. 
ONTORIA Antônio. et.al. Apreender com Mapas Mentais: uma estratégia para pensar e estudar. SP: Madras, 2008.

RODRIGUES, Eric Freitas. A avaliação e a tecnologia: a questão da verificação de aprendizagem no modelo de ensino híbrido. In. BACICH, Lilian; TANZI NETO, Adolfo; TREVISANI, Fernando de Mello. Ensino Híbrido: personalização e tecnologia na educação. Porto Alegre: Penso, 2015, p. 123-140.

SILVA, M. O fundamento comunicacional da avaliação da aprendizagem na sala de aula online. In. SILVA, M.; SANTOS, E. (Orgs.). Avaliação da aprendizagem em educação online: fundamentos, interfaces e dispositivos, relatos de experiência. São Paulo: Edições Loyola, 2006, p. 23-36.

SPINARDI, Janine Donato; BOTH, Ivo José. Blended Learning. O ensino híbrido e a avaliação da aprendizagem no Ensino Superior. v. 44. n. 1. Rio de Janeiro: B Téc-Senac, 2018.

VALENTE, José Armando. A sala de aula invertida e a possibilidade do ensino personalizado: uma experiência com a graduação em Midiologia. In. BACICH, Lilian; MORAN, José. (Orgs.). Metodologias Ativas para uma educação inovadora: uma abordagem teórico prática. Porto Alegre: Penso, 2018, p.26-44.

Prefácio: o ensino híbrido veio para ficar. In. BACICH, Lilian.; TANZI NETO, Adolfo; TREVISANI, Fernando de Mello. Ensino Híbrido: personalização e tecnologia na educação. Porto Alegre: Penso, 2015, p.13-17. 